\section{Educational Films}

A SESSION of the recent Sixth Imperial Social Hygiene Congress was devoted to the discussion of modern aids to education, including the cinematograph film and wireless.

Mr. A. C. Cameron, secretary to the City of Oxford Education Committee, emphasised the great value of the film as an Imperial educational force. No single country can offer to cinematography so fruitful a field as the British Empire. Yet the field has as yet scarcely been explored. It is hoped that the formation of a British Film Institute, now regarded as assured, will help to satisfy these Imperial needs.

Mr. Cameron gave a brief summary of the steps leading to the decision to form the Institute, its constitution and its main objects. The Film Institute, co-operating with corresponding bodies in the Dominions, will arrange for the exchange of film material, which will prove of great value in conveying information on geography and agricultural processes and in presenting documentary records of life and customs in different lands. Especially important is the presentation, to the backward races in the care of the British dominions overseas, of films which worthily present our culture. The conception of white civilisation which such races, with their limited powers of discrimination, are receiving from third rate melodrama is regarded as an international menace. A stock of films not merely "Not undesirable" but "likely to be beneficial" for display in specified territories is needed. One essential step is the formation of a Colonial film library.

In this connexion an interesting experiment is proposed in Malaya. The investigator, furnished with a motor lorry equipment, would not only show films of an entertaining as well as an educational nature, but also would produce films of value to the study of anthropology. So far finance has proved a difficulty, but it is hoped that the Film Institute will enable this to be overcome.

A second paper, by Mr. F. S. Hoare, director of research in the Industrial and Educational Department of the Western Electric Co., Ltd., discussed in detail the value of films in education. The launching of the British Film Institute should serve to bring teachers and producers of films into contact. Excellent portable projectors, giving a clear picture $10 \mathrm{ft}$. wide at distances of 50-60 ft., are now available. Experiments with sound films conducted in schools in the Middlesex area have demonstrated their value, both in teaching definite lessons and as an exceptionally effective means of illustration. Of special value is the power of awakening interest characteristic of films, which seem destined to prove a great help in the education of retarded pupils.

Amongst subjects lending themselves specially well to treatment with films, history and geography, industrial processes, scientific and medical processes (revealed by slow motion photography), and social hygiene were mentioned. Relatively new fields are the use of slow-motion pictures to illustrate correct movements in games and sport and of the sound film to teach modern languages.

It is hoped that one immediate result of the work of the British Film Institute will be a large increase in the production of films specially designed for educational purposes and a speeding up of the machinery for distribution and exhibition.

\section{Surface Currents in the North Sea}

A REPORT by Mr. John B. Tait of the Marine Laboratory at Aberdeen of the Fishery Board for Scotland (Fisheries, Scotland, Sci. Invest., No. 3 ; 1931) presents the results of a very detailed and painstaking cartographical analysis of the data accruing from certain large-scale experiments with surface floating drift-bottles carried out in 1911. Bottles were set afloat at positions selected to afford information concerning the surface water drift in the northern and middle areas of the North Sea and in the Faroe-Shetland Channel. Liberations were made in most months of the year.

The report in question, together with one which appeared somewhat earlier dealing with similar experiments made in 1910, and a third, wherein are to be found a statistical analysis and tabulated data relating to all such experiments carried out during five consecutive years immediately prior to the War, have added very greatly indeed to the body of knowledge on the subject.

Tait has shown conclusively that the North Sea receives a far greater access of surface water through the Shetland-Norway opening than via the ShetlandScotland passages ; that the belt of north-streaming surface waters along the Norwegian coast, representing the sole regular escape stream from the North Sea, may be of no greater width than some 50-60 miles; that there may be at times an actual exodus of water from the North Sea via the ScotlandShetland passages; that incursion of surface waters through these latter passages is subject to occasional stoppage due to a temporary north-flowing stream up the east coast of northern Scotland which pushes on up the eastern side of the Orkneys and Shetlands. $\mathrm{He}$ has, as the outcome of observing periodicities in the incidence of strandings from the same liberations, on certain stretches of coast, been able to demonstrate the intervention of delaying agencies which have operated to keep bottles at sea for multiples of particular time intervals.

In this connexion, Mr. Tait has demonstrated the existence of large eddies in the surface waters of the areas concerned--some of them already known, and others now discovered for the first time. Changes in the situation, size, and shape of the largest of these, which he has named the Great Northern North Sea Eddy, are shown to be capable of bringing about a profound modification of surface water flow over a very wide area of the North Sea.

\section{University and Educational Intelligence}

Edinburgh.-The Senatus Academicus of the University of Edinburgh has resolved to confer the honorary degree of LL.D. on the following, at the graduation ceremonial to be held on October 28, on the occasion of the celebration of the 350th anniversary of the foundation of the University : the Right Hon. Lord Buckmaster, Mr. J. W. Dowden, president of the Royal College of Surgeons, Edinburgh, Sir James Colquhoun Irvine, principal of the University of St. Andrews, Prof. Emile Legouis, Sir Ewen John Maclean, the Right Hon. Sir James Ian Macpherson, Sir Frederick Norton Kay Menzies, Dr. A. W. Pickard-Cambridge, vice-chancellor of the University of Sheffield, Sir Robert S. Rait, principal of the University of Glasgow, the Right Hon. Lord 
Rayleigh, Prof. William Rennie, Sir Edward SharpeySchafer, Miss Frances H. Simson, Sir George Adam Smith, principal of the University of Aberdeen, Dr. Robert Thin, president of the Royal College of Physicians, Edinburgh, and the Right Hon. William Johnston Thomson, Lord Provost of Edinburgh.

LoNDoN.-The Court has accepted with cordial thanks an offer made by the Royal Geographical Society of a set of reproductions of old maps.

The Rockefeller Foundation has made a grant of $£ 4,000$ for the reconstruction and equipment of additional laboratories of the Department of Physiology at University College, to accommodate expansion of Prof. A. V. Hill's work in biophysics.

ST. ANDREws.-The University Court has appointed Dr. B. M. Wilson to be professor of mathematics in University College, Dundee, in succession to Prof. J. E. A. Steggall, retired. An exhibitioner of Trinity College, Cambridge, Dr. Wilson was a Wrangler, and afterwards became a lecturer in mathematics at the University of Liverpool in 1920. He was advanced to the post of senior lecturer in 1926, and since 1931 has been in charge of the Department. His published work deals with the analytic theory of numbers, the theory of functions and of series, and the theory of integral equations. He holds the degree of D.Sc. of the University of Liverpool.

SHEFFIELD.-The following appointments, among others, have recently been made : Dr. L. B. Winter, demonstrator in physiology in the University of Manchester, to be lecturer in physiology; Mr. R. G. Bellams, to be assistant lecturer in mechanical engineering.

THE second award of the Brotherton research scholarship has been made to Mr. H. C. Millett, a student of the University of Leeds, who has just completed his B.Sc. degree course. The award will enable him to continue research work on the influence of sulphur compounds in furnace gases on the scaling of metals.

THE Science Scholarships Committee of the Royal Commission for the Exhibition of 1851 has made the following appointments to overseas scholarships for 1933, the subject and place of research being indicated in brackets: Canada:-on the recommendation of McGill University, Montreal : Dr. R. N. H. Haslam (physics, at the University of Leipzig); Dr. J. S. Tapp (physical chemistry, at the Imperial College of Science and Technology, London); on the recommendation of the University of Toronto: Mr. J. J. Rae (biochemistry, at the Lister Institute, London). Aus. tralia:- on the recommendation of the University of Adelaide: Mr. R. C. L. Bosworth (physics, at the University of Cambridge); on the recommendation of the University of Melbourne; Mr. E. H. S. Burhop (physics, at the University of Cambridge); on the recommendation of the University of Sydney : Mr. S. E. Williams (physies, at the University of Bristol or Durham). New Zealand:- on the recommendation of the University of New Zealand: Mr. E. R. Cooper (physics, at the University of Cambridge). South Africa:- -on the recommendation of the University of South Africa: Mr. J. E. Vanderplank (mycology, plant physiology and plant chemistry, at an institution in Europe).

\section{Calendar of Nature Topics}

\section{Curious Feeding Habit of Grebes}

In July most of the grebes' eggs in Great Britain will have hatched and adults and young will offer opportunity for fuller observation of a grebe habit about which much doubt exists. The stomachs of grebes almost always contain masses of feathers, and these feathers are often swallowed during the process of preening. But the swallowing is deliberate, and its possible purpose has given rise to many suggestions : that the feathers protect the walls of the stomach from sharp fish bones; that they prevent the passage of large undigested fragments into the intestine; that they retain small organisms in the stomach until they are digested; that they supply some chemical useful in digestion, and so on.

There is something to be said for the idea that the feathers may be used in making up pellets, along with indigestible fragments of food, which the bird will reject as casts, like those of birds of prey. On this point Dr. Josef Jirsik has collected evidence (Bull. école sup. agron., Brno, p. 1, 1929). Where only small insects occurred in the stomachs examined, very few feathers were found; where remains of fishes or of large insects, such as Dytiscus, were present, recently swallowed feathers were many, and in the stomach hard indigestible remains were felted together with feathers, although no trace of such appeared in the intestine. Finally, with the aid of a binocular telescope, Jirsik observed adult grebes making vomiting motions like those made by herons, as if they were actually rejecting 'casts' of food debris. On the other hand, the authors of the "Great Crested Grebe Enquiry of 1931" state that "there is no evidence at all of pellet formation". July is a good month to settle this problem of pellet formation by direct observation.

\section{Another Grebe Problem for July}

Even very young grebes are found to contain feathers in their stomachs; the feathers, however, are not their own, but those of the parent birds. How are the feathers obtained ? Messrs. Harrisson and Hollom "have seen a four-day chick given fourteen feathers in one day" (British Birds, 26, p. 149, 1932). Jirsik examined a chick still covered solely with down, and still containing yolk from the egg in its intestine; it was only a few hours old, yet it contained 13 adult feathers. Another chick from the same family, several hours older, contained 93 feathers; and three others, successively older, had each proportionally more feathers, all from the plumage of the mother. But whenever feathers begin to appear amongst the down of the chicks, as Jirsik found by examining three July coveys, these feathers are to be found in the stomachs of the chicks, plucked and swallowed by the chicks themselves. He insists that the parental feathers also have been plucked from the parent even by the very young chicks, although he offers no direct evidence, other than the statement that sometimes the feathers are from parts of the body which the parent cannot reach with its beak. The young, at any rate, have many opportunities of obtaining adult feathers, for a considerable proportion of their youth is spent huddled upon the back of the swimming parent. Although featherswallowing in the adults is often associated with 